\title{
New Transparent Composite Films based on Glass Cloth Reinforced Polyimides
}

\author{
Masaki Okazaki, Ken-ichi Fukukawa, Yoshihiro Sakata, Tatsuhiro Urakami, \\ Wataru Yamashita and Shoji Tamai \\ Advenced Materials Development Project, New Materials Development Center, \\ Mitsui Chemicals, Inc., 580-32 Nagaura, Sodegaura-City, Chiba 299-0265, Japan
}

Keywords : transparent polyimide, composite film, refractive index, coefficient of thermal expansion

\section{Introduction}

Polyimides (PIs) have been widely used in various fields owing to their outstanding properties with thermal and mechanical stability [1-3]. In general PIs have brown or yellow colors due to intra- and intermolecular charge transfer interactions [2]. Recently PIs with high transparency, that is colorless PIs, have attracted much attention in the applications as optoelectronic material because of their excellent thermal stability. There are many reports about transparent PI based on alicyclic PIs [1-9]. So far we also have been developed high transparent PIs based on semi-alicyclic PIs, which consist of 2,5(6)-bis(aminomethyl)bicyclo- [2.2.1]heptane (NBDA) as a diamine monomer and aromatic tetracarboxylic dianhydride [10]. However coefficient of thermal expansion (CTE) value of these transparent PIs, one of an important thermal property, was insufficient for the application to micro and optoelectronics. Hasegawa et al reported the semi-alicyclic PI having low CTE and high transparency but there are some limitations on the monomer structure and preparation procedure [3-5].

On the other hand, the development of organic and inorganic hybrid materials also has been paid a lot of attention because inorganic fillers are well-known materials to enhance the mechanical and thermal properties of organic polymers [11]. Many reports have been published concerning with composite films consisting of PI and inorganic materials $[1,11-16]$. And we also reported the PI composite film based on semi-alicyclic PIs and thermally treated talc in 2008 [17].

Thus we focused on the composition of PI and inorganic materials, glass cloth (GC), which was widely used industrially as fillers for plastic and rubber, to obtain transparent PIs having high thermal stability and low CTE. To prepare high transparent composite films, the refractive index (RI) of PIs has to be in agreement with RI of GC. So it is the most important point to control the RI of matrix transparent PIs.

In this study, we report the novel transparent materials having high thermal stability, high transparency and low CTE by the combination of semi-alicyclic transparent PI having NBDA structure and GC.

\section{Experimental}

2.1 Materials

Pyromellitic dianhydride (PMDA), 3,3',4,4' -biphenyltetracarboxylic dianhydride (s-BPDA), 4,4'-oxydiphthalic anhydride (ODPA), 3,3',4,4'diphenylsulfonetetracarboxylic dianhydride (DSDA), 3,3',4,4'-Benzophenonetetracarboxylic Dianhydride (BTDA), 4,4'-(hexafluoroisopropyridene)diphthalic anhydride (6FDA), were obtained commercially and used as received. NBDA was purified by distillation. N,Ndimethylacetamide (DMAc) was used as received. Glass cloth (E type, \#1067) was kindly supplied by Asahi Kasei E-Materials Corp. and used as received. 


\subsection{Polymer syntheses}

2.2.1 Polymerization of Poly(amic acid) (PAA-1 6)

NBDA $(0.5 \mathrm{~mol})$ in DMAc was added dropwise to a suspension of tetracarboxylic dianhydride $(0.5$ mol) in DMAc $(300 \mathrm{ml})$ under nitrogen at $0{ }^{\circ} \mathrm{C}$ for $3 \mathrm{~h}$. The solution was stirred at room temperature for $12 \mathrm{~h}$. An inherent viscosity of the resulting poly(amic acid) (PAA) in DMAc was $0.27 \sim 0.68$ $\mathrm{dL} / \mathrm{g}$ at a concentration of $0.5 \mathrm{~g} / \mathrm{dL}$ in DMAc at $35^{\circ} \mathrm{C}$.

\subsubsection{Polymerization of $\mathrm{PAA}-7$ and -8}

NBDA $(0.5 \mathrm{~mol})$ in DMAc was added dropwise to a suspension of BPDA (m mol) and 6FDA ( $\mathrm{n} \mathrm{mol})$ $(\mathrm{m}+\mathrm{n}=0.5 \mathrm{~mol} ; \mathrm{m} / \mathrm{n}=2 / 8,5 / 5)$ in DMAc $(300 \mathrm{ml})$ under nitrogen. The polymerization conducted same procedure as described above. An inherent viscosity of PAA-7 and -8 was determined to be 0.50 and $0.60 \mathrm{dL} / \mathrm{g}$, respectively.

\subsection{Preparation of PI films}

PAA solution was directly cast on a glass substrate using bar-coater, followed by thermal curing at the elevated temperature up to $270^{\circ} \mathrm{C}$ under nitrogen.

2.4 Preparation of composite films based on GC reinforced PIs

GC reinforced PI prepregs was prepared by impregnating the $\mathrm{GC}$ with PAA solution, followed by drying in the air, and then thermally baking at $270{ }^{\circ} \mathrm{C}$ under nitrogen. The prepregs were pressed under reduced pressure at $310^{\circ} \mathrm{C}$. The weight fraction of the PIs composite films was determined by thermogravimetry (TGA).

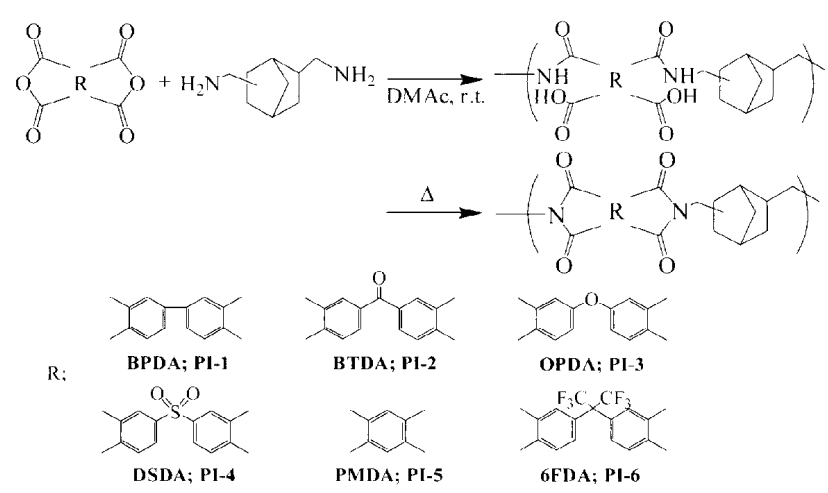

Scheme 1. Polymerization of poly(amic acid)s (PAAs) and polyimides (PIs)

\subsection{Measurements}

Thermal analyses were performed on a SHIMADZU TGA-50 thermal analyzer at a heating rate of $10{ }^{\circ} \mathrm{C} / \mathrm{min}$ for TGA and a SHIMADZU TMA-50 at a heating rate of $10^{\circ} \mathrm{C} / \mathrm{min}$ for thermal mechanical analysis (TMA) under air. RI at $589 \mathrm{~nm}$ is measured by Abbe's refractometer (DR-M2). Hazemeter (NDH2000; NIPPON DENSHOKU) was used for the measurement of light transmission and haze.

\section{Results and Discussion}

3.1 Polymer synthesis and properties of corresponding PI films

The RI of PIs has to be in agreement with RI of $\mathrm{GC}(1.558$ at $589 \mathrm{~nm})$ to prepare high transparent composites based on PIs and GC. So PI films based on NBDA and conventional tetracarboxylic dianhydride was prepared to get information of RI of homo-polyimide using NBDA as an alicyclic diamine monomer.

Polymerization of NBDA with conventional

Table 1. Properties of semi-alicyclic PIs using NBDA as a diamine monomer

\begin{tabular}{|c|c|c|c|c|c|c|}
\hline PIs & dianhydride & $\begin{array}{c}\text { Inherent viscosity }{ }^{* 1} \\
\mathrm{dL} / \mathrm{g}\end{array}$ & $\begin{array}{c}\mathrm{Td} 5{ }^{* 2} \\
{ }^{\circ} \mathrm{C}\end{array}$ & $\begin{array}{c}\mathrm{Tg}^{* 3} \\
{ }^{\circ} \mathrm{C}\end{array}$ & $\begin{array}{c}\mathrm{CTE}^{* 4} \\
\mathrm{ppm} / \mathrm{K}\end{array}$ & $\mathrm{RI}^{{ }^{* 5}}$ \\
\hline PI-1 & BPDA & 0.62 & 470 & 254 & 42 & 1.641 \\
\hline PI-2 & BTDA & 0.66 & 402 & 232 & 47 & 1.627 \\
\hline PI-3 & ODPA & 0.68 & 450 & 211 & 54 & 1.624 \\
\hline PI-4 & DSDA & 0.27 & 431 & 247 & 48 & 1.620 \\
\hline PI-5 & PMDA & 0.62 & 463 & 290 & 48 & 1.600 \\
\hline PI-6 & 6FDA & 0.66 & 400 & 248 & 49 & 1.547 \\
\hline
\end{tabular}

1) Poly(amic acid); measured at a concentration of $0.5 \mathrm{~g} / \mathrm{dL}$ in DMAc at $35^{\circ} \mathrm{C}, 2$ ) Measured by TGA 3) Determined by TMA, 4) CTE was calculated between $100-200^{\circ} \mathrm{C}, 5$ ) Measured by Abbe's refractometer (DR-M2) 
tetracarboxylic dianhydride (PMDA, s-BPDA, ODPA, DSDA, BTDA, 6FDA) was carried out in DMAc at room temperature for $12 \mathrm{~h}$ (Scheme 1). The gradual addition of alicyclic diamine solution into the tetracarboxylic dianhydride suspension method, which is the reverse procedure for the normal polymerization of PAAs, was adopted to avoid salt formation of alicyclic diamine with carboxylic acid. Each polymerization reactions proceeded smoothly and produced desired PAAs with inherent viscosity ca $0.6 \mathrm{dL} / \mathrm{g}$. PAAs solution obtained here were cast on a glass substrate using bar-coater and converted to the corresponding PI films by thermal treatment at $270^{\circ} \mathrm{C}$ under nitrogen. The thermal and RI properties of PIs were measured and summarized in Table 1. As a result, it was found that RI of PI-1 5 was much higher and PI-6 was lower than that of GC. So copolymerization of PI-6 with PI-1 was performed to control RI of PI because BPDA is one of very conventional monomer and PI-1 has moderate glass transition temperature ( $\mathrm{Tg})$ in terms of processability.

3.2 Determination of molecular ratio of PI-1 and PI-6
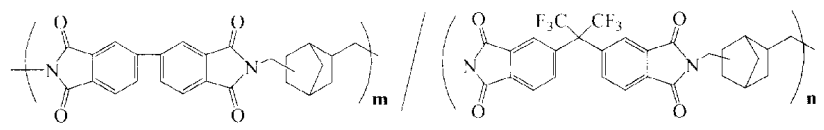

$\mathrm{m} / \mathrm{n}=0 / 10,2 / 8,5 / 5,10 / 0$

Scheme 2. Structure of co-polymers

Co-polymerization of PI-1 and PI-6 was carried out at the ratio of 2/8 (PI-7) and 5/5 (PI-8) (Scheme 2 ), and the relationship between PI-6 ratio and its RI was investigated. As shown in Figure 1, they have a liner relationship, the RI decreases with increasing the PI-6 ratio. Based on this finding, $\mathrm{PI}-1 / \mathrm{PI}-6$ ratio was determined to be $14 / 86$ to be in

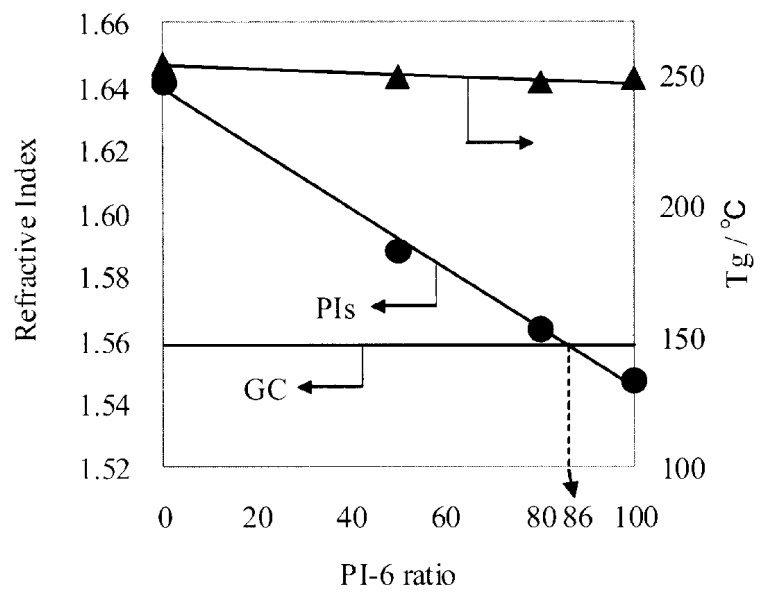

Figure 1. Relationship between PI-6 ratio and its RI agreement with RI of GC.

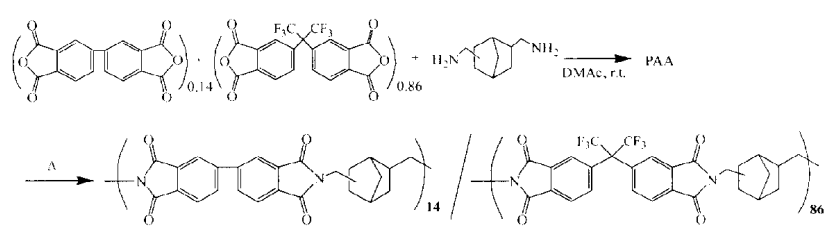

Scheme 3. Structure of copolymer (PI-9)

Thus co-polymerization of BPDA, 6FDA and NBDA was conducted in DMAc at room temperature for $12 \mathrm{~h}$ and corresponding PI (PI-9) film was prepared from the PAA (PAA-9) solution by thermal treatment at $270^{\circ} \mathrm{C}$ (Scheme 3). The thermal and optical properties of PI-9 film were shown in Table 2. It was found the PI-9 film was in agreement with RI of GC. Furthermore, although the film has little high CTE, it showed high transparency and glass transition temperature.

Table 2. Properties of PI-9

\begin{tabular}{|c|c|c|c|c|c|}
\hline $\begin{array}{c}\text { Thickncss } \\
\mu \mathrm{m}\end{array}$ & $\begin{array}{c}\mathrm{Td}^{*}{ }^{*} \\
{ }^{\circ} \mathrm{C}\end{array}$ & $\begin{array}{c}\mathrm{Tg}{ }^{* 2} \\
{ }^{\mathrm{C}}\end{array}$ & $\begin{array}{c}\mathrm{CTE}^{* 3} \\
\mathrm{ppm} / \mathrm{K}\end{array}$ & $\begin{array}{c}\text { Light } \\
\text { Transmittance } \\
\%\end{array}$ & $\mathrm{RI}^{* 5}$ \\
\hline 50 & 450 & 246 & 46 & 90.3 & 1.558 \\
\hline
\end{tabular}

1) Measured by TGA, 2) Determined by TMA, 3) (TE was calculated between 100$\left.200^{\circ} \mathrm{C}, 4\right)$ Estimated by hazemeter, 5) Determined by Abbe's refractometer

3.3 Preparation of the transparent composites films based on PI-9 and GC

GC reinforced PI prepregs was prepared by impregnating the GC with PAA (PAA-1,-6,-9) solution, followed by drying in the air, and then thermally baking at $270{ }^{\circ} \mathrm{C}$ under nitrogen. Then the prepregs were pressed under reduced pressure at $310^{\circ} \mathrm{C}$.

The properties of transparent composites of PIs and GC obtained here showed in Table 3. The composite films based on PAA- 1 and PAA-6, which is not in agreement with $\mathrm{RI}$ of $\mathrm{GC}$, has poor transparency. On the contrary, it was found the composite consisting of PAA-9 and GC showed high transparency, thermal stability and low CTE,

Table 3. Properties of transparency composites PI films

\begin{tabular}{|c|c|c|c|c|c|}
\hline $\begin{array}{c}\text { PI-1/PI-6 } \\
\text { ratio }\end{array}$ & $\begin{array}{c}\text { Thickness } \\
\mu \mathrm{m}\end{array}$ & $\mathrm{RI}^{* 1}$ & $\begin{array}{c}\text { Light } \\
\text { transmittance } \\
\%\end{array}$ & $\begin{array}{c}\text { Haze *2 } \\
\%\end{array}$ & $\begin{array}{c}\text { CTE *3 } \\
\mathrm{ppm} / \mathrm{K}\end{array}$ \\
\hline $14 / 86$ & 42 & 1.558 & 90.6 & 5.0 & 13.0 \\
\hline $14 / 86$ & 63 & 1.558 & 90.7 & 5.1 & 17.6 \\
\hline $100 / 0$ & 80 & 1.641 & 88.8 & 83.9 & - \\
\hline $0 / 100$ & 60 & 1.547 & 86.9 & 10.2 & - \\
\hline
\end{tabular}

1) Determined by Abbe's refractometer, 2) Estimated by hazemeter, 3) (TE was calculated between $100-200^{\circ} \mathrm{C}$ 


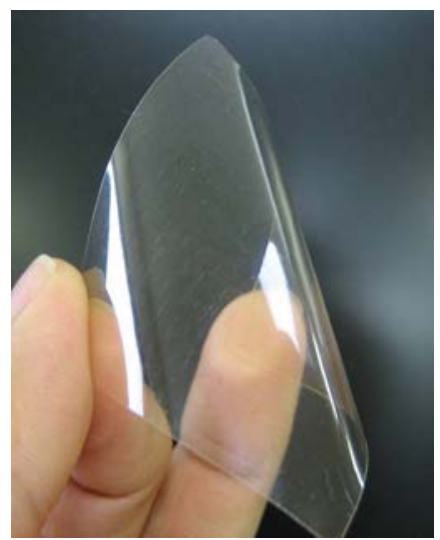

Figure 2. Composite film of GC reinforced PI-9

which do not depend on film thickness (Table 3, Figure 2).

In addition, the relationship between resin content and CTE was shown in Figure 3. This indicates the control of CTE can be possible to control resin content for GC.

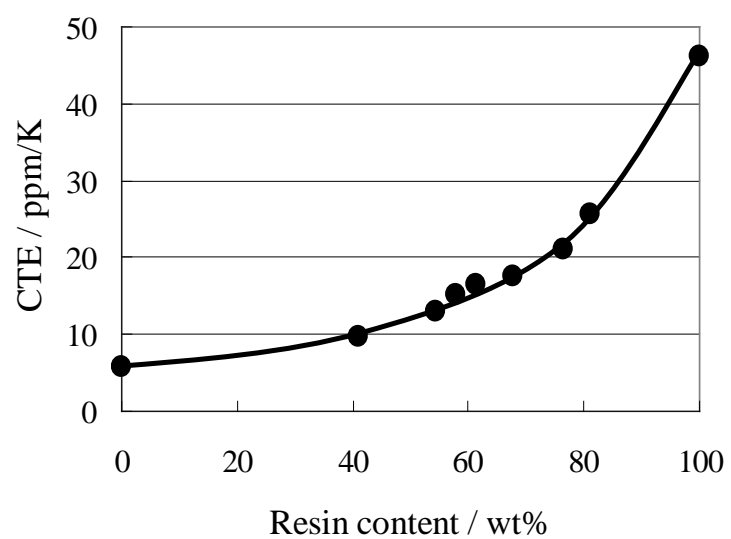

Figure 3. Relationship between resin content in composite film and its CTE

In conclusion, the control of RI of transparent $\mathrm{PI}$ was performed by co-polymerization of conventional tetracarboxylic dianhydride with an alicyclic diamine, NBDA and BPDA and 6FDA was selected as a tetracarboxylic dianhydride monomer. A nd the mole ratio was determined to be $14 / 86$ to prepare transparent composite film with $\mathrm{GC}$. The obtained composite films have high transparency, thermal stability and low CTE. The CTE also can be controlled by controlling resin content of composite filem.

\section{References}

[1] The Latest Polyimides: Fundamentals and pplications, R.Yokota et al, Eds., NTS, Tokyo, 2010 (in J apanese)

[2] M . I. Bessonov, M. M. K oton, V.V. K udryavtsev, L. A. Laius: 'Polyimides: Thermally Stable Polymers', Consultants Bureau, A Division of Plenum Publishing Co., New York, (1987).

[3] M. Hasegawa and K . Horie, Prog.Polym.Sci, . 26 (2001) 259.

[4] M. Hasegawa, High Perform. Polym., 13 (2001) S93-S106.

[5] M. Hasegawa, M. Horiuchi, Y. Wada, High Perform. Polym., 19, (2007) 175.

[6] T. Matsumoto, Current Trends in Polymer Science, 13, (2009) 107.

[7] A. Mathews, I. Kim, C. Ha, Macromolecular Research, 15(2), (2007) 114.

[8]G. Hougham, P. E. Cassidy, K. Johns, and T. Davidson, eds. 'Fluoropolymers 1: Synthesis'and 'Fluoropolymers 2: Properties', Kluwer Academic/P lenum Publishers, N ew York (1999).

[9] N. Y ou, Y. Suzuki, T. Higashihara, S. A ndo, M. U eda, Polymer $\mathbf{5 0}$ (2009) 789.

[10] W. Yamashita, K. Watanabe, H. Oikawa and H. Ito, W02002-010253

[11] Hybrid M aterials, Synthesis, Characterization, and A pplications, G.. Kickelbick Eds., Wiley-VCH Verlag G mbH \& Co. (2007).

[12] A. M orikawa, H. Yamaguchi, M. Kakimoto, Y. Imai: Chem.M ater., 6, (1994) 913.

[13] Y. Han, J. Wakita, S. Kuroki, X. Wang and S. Ando: J. Photopolym. Sci. Technol., 21, (2008) 143.

[14] D. Yorifuji, A. M atsumura, T. A oki, Y. Tashiro, S. Kuroki and S. Ando: J. Photopolym. Sci. Technol., 22, (2009) 447.

[15] K. Yano, A. Utsuki and A. Okada: J. Polym. Sci. Part A Polym.Chem., 35, (1997) 2289.

[16] J. L. Hedrick, H.-J. Cha, R. D. M iller, D. Y. Yoon, H. R. Brown, S. Srinivasan, and R. Di Pietro, R. F. Cook, J. P. Hummel, D. P. K laus, E. G. Liniger, and E. E. Simonyi: Macromolecules, 30, (1997) 8512.

[17] K. Fukukawa, I. Fujio, W. Yamashita, and Shoji Tamai, J. Photopolym. Sci. Technol., 21 (2008), 101 